\author{
Henry I. Mosberg \\ Division of Medicinal \\ Chemistry, \\ College of Pharmacy, \\ University of Michigan, \\ Ann Arbor, MI 48109-1065
}

\section{Complementarity of $\delta$ Opioid Ligand Pharmacophore and Receptor Models}

\begin{abstract}
The elaboration of a pharmacophore model for the $\delta$ opioid receptor selective ligand JOM-13 (Tyr-c[D-Cys-Phe-D-Pen]OH) and the parallel, independent development of a structural model of the $\delta$ receptor are summarized. Although the backbone conformation of JOM-13's tripeptide cycle is well defined, considerable conformational lability is evident in the Tyr ${ }^{l}$ residue and in the Phe $e^{3}$ side chain, key pharmacophore elements of the ligand. Replacement of these flexible features of the ligand by more conformationally restricted analogues and subsequent correlation of receptor binding and conformational properties allowed the number of possible binding conformations of JOM-13 to be reduced to two. Of these, one was chosen as more likely, based on its better superposition with other conformationally constrained $\delta$ receptor ligands. Our model of the $\delta$ opioid receptor, constructed using a general approach that we have developed for all rhodopsin-like $G$ protein-coupled receptors, contains a large cavity within the transmembrane domain that displays excellent complementarity in both shape and polarity to JOM-13 and other $\delta$ ligands. This binding pocket, however, cannot accommodate the conformer of JOM-13 preferred from analysis of ligands, alone. Rather, only the "alternate" allowed conformer, identified from analysis of the ligands but "disfavored" because it does not permit simultaneous superposition of all pharmacophore elements of JOM-13 with other $\delta$ ligands, fits the binding site. These results argue against a simple view of a single, common fit to a receptor binding site and suggest, instead, that at least some binding site interactions of different ligands may differ. (C) 2000 John Wiley \& Sons, Inc. Biopoly 51: 426-439, 1999
\end{abstract}

Keywords: bioactive conformation; conformationally restricted peptides; $G$ protein coupled receptors; ligand-receptor interactions; molecular recognition; opioid peptides

\section{INTRODUCTION}

An understanding of the details of molecular recognition between a ligand and its macromolecular target is central to efforts at truly "rational" (structurebased) drug design. For ligands whose targets are water-soluble proteins, such an understanding can often be gained directly by $\mathrm{x}$-ray structure determination of the ligand-protein complex. This approach has been especially valuable for probing the molecular details of enzyme-substrate/inhibitor interactions and has facilitated the development of effective inhibitors of many enzymes with perhaps the most notable and certainly the most thoroughly studied being HIV protease. ${ }^{1}$ The elucidation of ligand interactions with membrane proteins, however, poses serious problems that arise from the difficulty of high-resolution structure determination of these proteins due to limited crystallization successes and difficulties in maintaining native-like function when the protein is removed from the membrane. Consequently, despite the fact that $\sim 30 \%$ of the proteins encoded in the genome are predicted to have at least one transmembrane segment, ${ }^{2}$ membrane proteins constitute only $\sim 0.2 \%$ of all reported high-resolution experimental protein structures. Given the considerable obstacles to struc-

Biopolymers (Peptide Science), Vol. 51, 426-439 (1999)

(C) 2000 John Wiley \& Sons, Inc. 


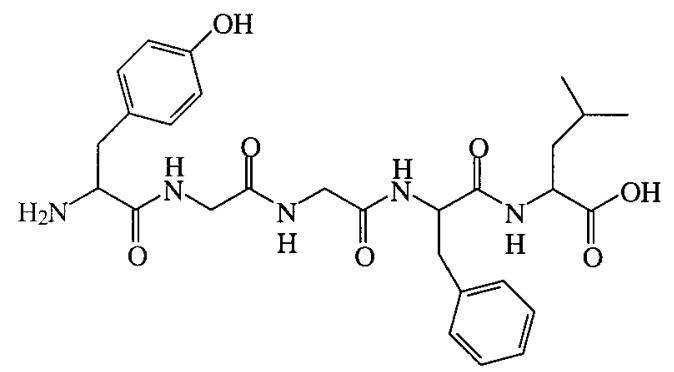

Leu-enkephalin

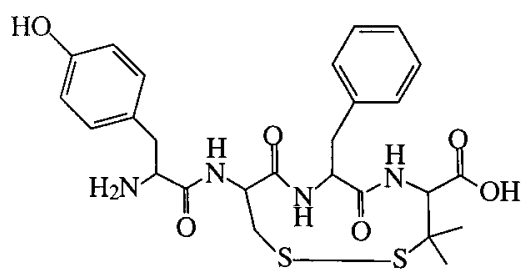

JOM-13<smiles>CSCCC(NC(=O)C(Cc1ccccc1)NC(=O)CNC(=O)CNC(=O)C(N)Cc1ccc(O)cc1)C(=O)O</smiles>

Met-enkephalin

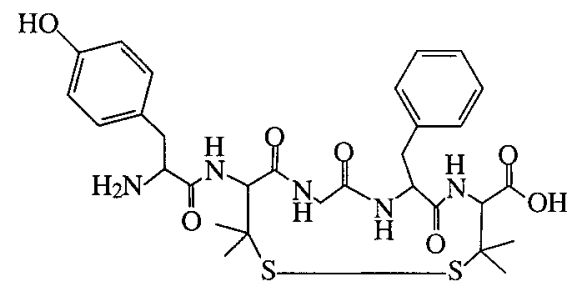

DPDPE

FIGURE 1 Peptide ligands for the $\delta$ opioid receptor.

tural elucidation of membrane proteins, information about ligand interactions with membrane-bound receptors has typically been limited to that which can be inferred from ligand structure-activity information and studies aimed at revealing the ligand's binding conformation. The inferred receptor binding site features are necessarily quite crude and fall far short of the level of detail needed for "rational" design.

Opioid ligand-receptor interactions provide a typical example of this scenario. Opioid receptors belong to the rhodopsin-like $\mathrm{G}$ protein-coupled receptor (GPCR) family, a large ( $>1000$ sequences) group of structurally related transmembrane proteins that includes receptors for ligands of vastly varying size (biogenic amine to glycoprotein). ${ }^{3}$ Despite many years of study, no experimental, high-resolution structure has been determined for any GPCR. Consequently, efforts to explain the molecular basis for opioid ligand-receptor interaction have focused on structural and conformational features of the ligand. For flexible native ligands (such as the endogenous opioid peptides), whose conformations are highly dependent on their environment, conformationally constrained analogues must be employed if extrapolation of the free ligand's conformational features to that of the bound ligand is to have any significance. In the first part of this review, the development of a $\delta$ opioid ligand pharmacophore model, based upon a series of such conformationally constrained ligands, will be described.

Although no high-resolution experimental structures are available for any GPCR, a large number of structural models have been proposed. The approaches used to generate these structures have encompassed many computational/modeling methods and have typically started from low resolution electron microscopy (EM) data for rhodopsin. ${ }^{4-6}$ Often the resulting models are rather crude but are nonetheless useful for the design of receptor mutagenesis studies aimed, for example, at delineating residues participating in ligand binding. Several years ago we began the development of a new approach for constructing more accurate models of GPCRs. ${ }^{7}$ This approach is based upon the analysis of a large number of GPCR sequences to identify proximal pairs of hydrogen-bonded residues and the use of the resulting distance constraints for distance geometry refinement of an initial, crude model based upon the low-resolution rhodopsin EM data. As discussed below, the resulting $\sim 30$ models, which include rhodopsin ${ }^{7}$ and the $\delta, \mu$, and $\kappa$ opioid receptors, ${ }^{8}$ are consistent with a vast collection of experimental data and are supported by structural and energetic considerations.

The existence of a reliable $\delta$ opioid ligand pharmacophore model and the wealth of structure activity data available for $\delta$ ligands provide the opportunity 


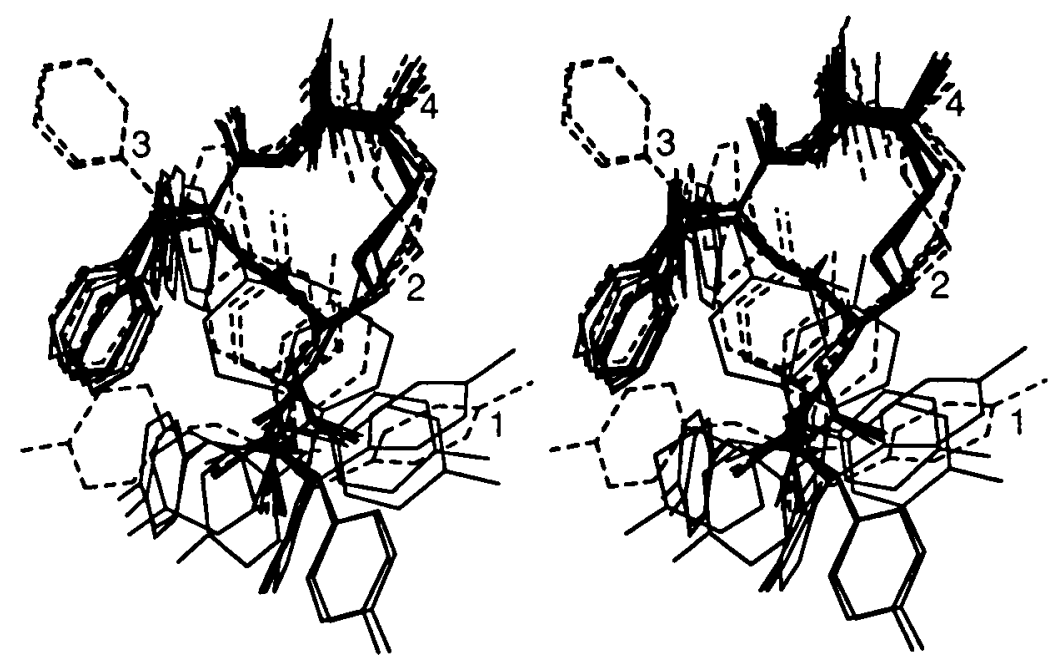

FIGURE 2 Superposition (stereoview) of 20 lowest energy conformers ( $\Delta G<3 \mathrm{kcal} / \mathrm{mol}$ ) of JOM-13. Dashed and solid lines denote two families differing in disulfide geometry. Reprinted with permission from Journal of the American Chemical Society, 1994, vol. 116, p. 430.

for verification of our $\delta$ opioid receptor model through ligand docking. In this report we review the development of both a $\delta$ ligand pharmacophore model and a high-resolution model of the $\delta$ receptor, and demonstrate that docking of these two independently derived structures is consistent with $\delta$ ligand structure-activity information.

\section{THE DEVELOPMENT OF A $\delta$ OPIOID LIGAND PHARMACOPHORE MODEL}

Since direct structural analysis of a ligand-receptor complex usually presents severe experimental difficulties, the development of a model for ligand-receptor binding typically relies on evaluation of the ligand's bioactive conformation, determined in the absence of receptor. For the necessary extrapolation of the "receptor-free" solution or solid state ligand conformation to that of the ligand bound to the receptor to be valid, the ligand must have limited conformational lability to assure that its conformation is environment independent. The native opioid pentapeptides, leucine- and methionine-enkephalin (Figure 1), however, are quite flexible, and hence are unsuited for such study. The incorporation of side-chain to sidechain disulfide cyclization in the $\delta$ receptor selective analogue [D-Pen ${ }^{2}$, D-Pen ${ }^{5}$ enkephalin (Tyr-c[D-PenGly-Phe-D-Pen]OH, DPDPE, Figure 1$)^{9}$ significantly reduces conformational freedom, and consequently, DPDPE has been a frequent target for conformational analysis. ${ }^{10-14}$ Many of these conformational studies have resulted, however, in discrepant conclusions, the likely result of residual conformational freedom in DPDPE. The most likely source of this flexibility in the DPDPE backbone is the Gly residue. While pursuing several approaches to reduce the backbone flexibility of DPDPE, we examined the effect of simply eliminating this Gly residue. This led, in a straightforward way, to the tetrapeptide Tyr-c[D-Cys-PheD-Pen]OH (JOM-13, Figure 1), ${ }^{15}$ which displays high $\delta$ receptor affinity, while retaining substantial $\delta$ selectivity.

A conformational search/molecular mechanics study of JOM-13 revealed the existence of two major conformational families of the cyclic tripeptide fragment. ${ }^{16}$ Both conformational families exhibited similar conformations within the backbone of this tripeptide segment, but differed in the conformational features of the disulfide. These results were supported by nmr data ${ }^{16}$ that clearly identified two sets of resonances whose differences were most pronounced for the $\mathrm{D}-\mathrm{Cys}^{2}$ and $\mathrm{D}-\mathrm{Pen}^{4}$ residues, consistent with the presence of two distinct disulfide conformers. $x$-Ray crystallography of JOM- $13^{16}$ confirmed the existence of two conformers of the tripeptide cycle in the unit cell, one conformer falling within each of the two major conformational families found in the computational study.

The excellent agreement among the different conformational studies provided convincing evidence that the backbone conformation of the tripeptide cycle of JOM-13 is well defined and environment independent. However, it was clear from the conformational search/molecular mechanics study that the backbone conformation of the exocyclic $\mathrm{Tyr}^{1}$ residue and the 


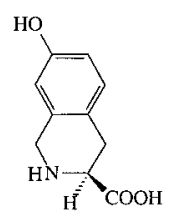

$L$-HO-Tic

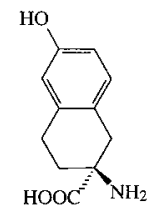

$L$-Hat

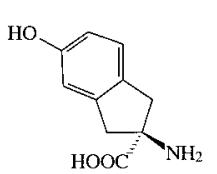

$L$-Hai
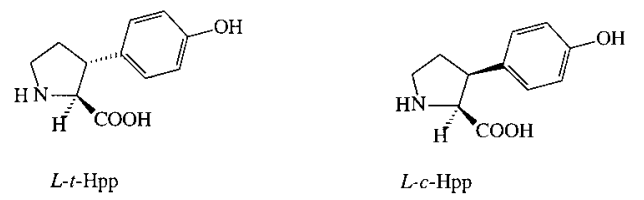

FIGURE 3 Conformationally constrained $\mathrm{Tyr}^{1}$ replacements.

side-chain conformations for $\mathrm{Tyr}^{1}$ and $\mathrm{Phe}^{3}$ are quite variable. This can be seen in Figure 2, which depicts the superposition of the 20 lowest energy conformers found for JOM-13. In Figure 2 both the well-defined conformational features of the cyclic tripeptide backbone and the conformational lability of Tyr and of the Phe side chain are apparent. Unfortunately, these flexible residues contain the key structural features for opioid activity ("tyramine" amino and phenolic groups and a second aromatic moiety) - hence the constraints contained within JOM-13 are insufficient for elucidating the key features of the bioactive conformation.

The conformational lability of JOM-13 leaves several features of the bioactive conformation unresolved: $\psi^{1}$ (the angle about the $\mathrm{Tyr}^{1} \mathrm{C}^{\alpha}-\mathrm{CO}$ bond); $\varphi^{2}$ (the angle about the $\mathrm{Cys}^{2} \mathrm{~N}^{\alpha}-\mathrm{C}^{\alpha}$ bond); and $\chi^{11}$ and $\chi^{13}$ (the angles about the $\mathrm{C}^{\alpha}-\mathrm{C}^{\beta}$ bonds of $\mathrm{Tyr}^{1}$ and $\mathrm{Phe}^{3}$, respectively). In order to remove this conformational uncertainty, we designed sets of analogues in which conformationally labile components of JOM-13 were replaced by more conformationally well-defined elements.

\section{Conformational Requirements of $\mathrm{Tyr}^{\mathbf{1}}$}

In the first set of analogues, ${ }^{17}$ the $\mathrm{Tyr}^{1}$ residue of JOM-13 was replaced by several conformationally constrained analogues of Tyr (Figure 3). Each of these Tyr replacements has reduced flexibility compared to Tyr, and importantly, each can sample a different subset of the conformational space available to Tyr. Consequently, if two or more of the analogues examined display similar binding affinity as JOM-13, then the search for the bioactive conformational features of $\mathrm{Tyr}^{1}$ in JOM-13 is simplified to a search within the intersection of conformational space available to the $\mathrm{Tyr}^{1}$ replacements in these active analogues. If, on the other hand, only one of the Tyr-replacement analogues displays "native-like" binding affinity, then the bioactive conformation can be sought within the conformational space available only to that $\mathrm{Tyr}^{1}$ analogue and Tyr itself. Of course, if none of the constrained $\mathrm{Tyr}^{1}$ analogues of JOM-13 retains good binding affinity, the features of the bioactive conformation remain obscure. Fortunately, as shown in Table I, the t-Hpp ${ }^{1}$ and $\mathrm{c}-\mathrm{Hpp}^{1}$ [trans- and cis-3-(4'-hydroxy)phenylproline, respectively] analogues of JOM-13 displayed $\delta$ binding affinities comparable to that of JOM-13, itself. ${ }^{17}$ Comparison of the conformational tendencies of these two diastereomeric residues reduced the conformational possibilities for the Tyr residue of JOM-13 to two, differing only in the possible choices of $\varphi^{2}$ (the angle about the $\mathrm{N}^{\alpha}-\mathrm{C}^{\alpha}$ bond of D-Cys ${ }^{2}$ ), which could be either $\sim 160^{\circ}$ or $\sim 70^{\circ}$. In both conformers $\chi^{1}$ for the Tyr side chain is $\sim 180^{\circ}$ and $\psi^{1}$ (the angle about the Tyr $\mathrm{C}^{\alpha}-\mathrm{CO}$ bond) is $\sim 160^{\circ}$. Although both candidate bioactive conformers are energetically similar, the conformation with $\varphi^{2}$ $\sim 160^{\circ}$ allowed better superposition of the high affinity c-Hpp ${ }^{1}, \mathrm{t}-\mathrm{Hpp}^{1}$, and $\mathrm{Tyr}^{1}$ analogues with the moderate affinity Hat ${ }^{1}$ (6-hydroxy-2-aminotetralin-2carboxylic acid) and $\mathrm{Hai}^{1}$ (6-hydroxy-2-aminoindan2 -carboxylic acid) analogues. Consequently, we proposed ${ }^{17}$ that this "preferred" conformer is more likely to be the binding conformation than is the "alternate" conformer (with $\varphi^{2} \sim 70^{\circ}$ ). This proposal was based on the seemingly reasonable assumption that the binding conformations of structurally similar ligands should be similar and that these similar ligands should interact in the same manner with the receptor. This assumption is reconsidered below. To summarize, then, the synthesis, pharmacological testing, and conformational analysis of JOM-13 analogues with con-

Table I Binding Affinities of JOM-13 and $\mathbf{X}^{1}$ Analogues ${ }^{\mathbf{a}}$

\begin{tabular}{lccc}
\hline Ligand & $\begin{array}{c}K_{i}(\mu) \\
(\mathrm{n} M)\end{array}$ & $\begin{array}{c}K_{i}(\delta) \\
(\mathrm{n} M)\end{array}$ & $\begin{array}{c}K_{i}(\mu) / \\
K_{i}(\delta)\end{array}$ \\
\hline JOM-13 & 51.5 & 0.744 & 69.2 \\
{$\left[t-\mathrm{Hpp}^{1}\right] \mathrm{JOM}-13$} & 105 & 0.66 & 159 \\
{$\left[c-\mathrm{Hpp}^{1}\right] \mathrm{JOM}-13$} & 722 & 2.39 & 302 \\
{$\left[\mathrm{Hai}^{1}\right] \mathrm{JOM}-13$} & 838 & 12.5 & 67.0 \\
{$\left[\mathrm{Hat}^{1}\right] \mathrm{JOM}-13$} & 231 & 19.9 & 11.6 \\
{$\left[\mathrm{D}^{\mathrm{H}} \mathrm{Hat}^{1}\right] \mathrm{JOM}-13$} & 310 & 23.7 & 13.8 \\
\hline
\end{tabular}

${ }^{\text {a }}$ Binding affinities at $\mu$ and $\delta$ receptors were determined by displacement of $\left[{ }^{3} \mathrm{H}\right] \mathrm{DAMGO}\left(\left[\mathrm{D}-\mathrm{Ala}^{2}, \mathrm{NMePhe}^{4}, \mathrm{Gly}^{5}\right.\right.$-ol $]$ enkephalin) and $\left[{ }^{3} \mathrm{H}\right] \mathrm{DPDPE}$, respectively. ${ }^{17}$ 
<smiles>C=C1C2CNC(CC2C(C)=O)C1c1ccccc1</smiles><smiles>[R1]C1C2CCC(C(C)=O)(CN2)C1C</smiles>

\section{(2S, 3S)MePhe}

$$
\chi^{1}=-60^{\circ}
$$

(2S, 3R)MePhe

$$
\chi^{1}=180^{\circ}
$$

FIGURE 4 Sterically preferred side-chain conformers of $\beta$ MePhe.

formationally constrained $\mathrm{Tyr}^{1}$ replacements allowed key elements of the JOM-13 pharmacophore to be determined $\left(\chi^{11} \sim 180^{\circ}, \psi^{1} \sim 160^{\circ}\right)$ or limited $\left(\varphi^{2}\right.$ $\sim 160^{\circ}$ or $70^{\circ}$ ). All that remained, then, was to deduce the binding conformation of the $\mathrm{Phe}^{3}$ side chain.

\section{Conformational Requirements of $\mathrm{Phe}^{3}$}

Figure 2 demonstrates that, in low energy conformers of JOM-13, the Phe side chain can assume any of the staggered $\chi^{1}$ conformers $\left(\chi^{1}=-60^{\circ},+60^{\circ}\right.$, or $\left.180^{\circ}\right)$. Substitution of $\mathrm{Phe}^{3}$ in JOM-13 by the des-hydroxy counterparts (and hence Phe analogues) of the Tyr replacements shown in Figure 3 and subsequent correlation of binding affinity and conformational tendencies is a logical approach for identifying $\chi^{1}$ of Phe in the JOM-13 bioactive conformation. Unfortunately, we observed that all these replacements resulted in rather large ( $>50$-fold) reductions in binding affinity, which is probably attributable to distortion of the backbone conformation of the cyclic tripeptide caused by cyclization of the Phe side chain to the backbone $\mathrm{N}^{\alpha}$ or $\mathrm{C}^{\alpha}$. As an alternate approach, we prepared the
4 stereoisomers of $\beta$-methyl Phe and incorporated each of these as $\mathrm{Phe}^{3}$ replacements in JOM-13. ${ }^{18}$ The rationale behind this well-studied approach is to exploit the steric property of the $\beta$-methyl to favor one conformation of $\chi$ (Figure 4). Table II summarizes the $\mu$ and $\delta$ binding affinities of the four $\beta \mathrm{MePhe}^{3}$ analogues of JOM-13 and additionally provides the relative energies of the residue 3 rotamers calculated for each analogue. ${ }^{18}$ As can be seen from this table, in [(2S, 3S)-MePhe $\left.{ }^{3}\right] J O M-13$ and [(2R, 3R)-MePhe $\left.{ }^{3}\right]-$ JOM-13, the analogues displaying the highest $\delta$ affinity, the same spatial orientation of the phenyl side chain is strongly favored: the $\chi^{1}=-60^{\circ}$ rotamer of the former is favored by $1.5-2.2 \mathrm{kcal} / \mathrm{mole}$, while the spatially equivalent (since the $\alpha$ stereochemistry is inverted) $\chi^{1}=60^{\circ}$ rotamer of the latter is favored by more than $6 \mathrm{kcal} / \mathrm{mole}$ ! These results strongly implicate the presence of the $\chi^{1}=-60^{\circ}$ rotamer of $\mathrm{Phe}^{3}$ in the binding conformer of JOM-13.

As a further test of this conclusion, we prepared JOM-13 analogues in which $\mathrm{Phe}^{3}$ was replaced by either dehydro-Z-phenylalanine $\left(\Delta^{\mathrm{Z}}\right.$-Phe) or dehydroE-phenylalanine $\left(\Delta^{\mathrm{E}}\right.$-Phe). ${ }^{19}$ Conformational analysis had revealed that the former of these analogues could be superimposed with JOM-13 in which the Phe $\chi^{1}$ $=-60^{\circ}$, while the latter analogue superimposes with JOM-13 conformers with the Phe $\chi^{1}=180^{\circ}$. The observation that $\left[\Delta^{\mathrm{Z}}-\mathrm{Phe}^{3}\right] \mathrm{JOM}-13$ displays $\delta$ receptor binding affinity comparable to that of JOM-13, itself $\left(K_{i}=2.3\right.$ vs $\left.0.74 \mathrm{nM}\right)$, while $\left[\Delta^{\mathrm{E}}-\mathrm{Phe}^{3}\right] \mathrm{JOM}-$ 13 binds significantly more poorly $\left(K_{i}=45 \mathrm{n} M\right)^{19}$ provides strong support for the proposed bioactive conformation of the Phe side chain. Combined with the conformational analysis of the JOM-13 tripeptide cycle and the elucidation of the $\mathrm{Tyr}^{1}$ binding conformation, the determination of the Phe binding rotamer as $=-60^{\circ}$ allowed a complete binding conformation

Table II Binding Affinities and Energy Differences of $\mathrm{X}^{3}$ Side-Chain Rotamers of JOM-13 and $\beta$ MePhe ${ }^{3}$

\begin{tabular}{|c|c|c|c|c|c|}
\hline \multirow[b]{2}{*}{ Ligand } & \multirow[b]{2}{*}{$K_{i}(\mu)(\mathrm{n} M)$} & \multirow[b]{2}{*}{$K_{i}(\delta)(\mathrm{n} M)$} & \multicolumn{3}{|c|}{$\begin{array}{c}\text { Relative Energy }(\mathrm{kcal} / \mathrm{mol}) \\
\text { of } \chi^{1} \text { Rotamers }\end{array}$} \\
\hline & & & $-60^{\circ}$ & $180^{\circ}$ & $60^{\circ}$ \\
\hline JOM-13 & 51.5 & 0.744 & 0.1 & 0.0 & 0.9 \\
\hline$\left[(2 \mathrm{~S}, 3 \mathrm{R}) \mathrm{MePhe}^{3}\right] \mathrm{JOM}-13$ & 1000 & 12.3 & 0.2 & 0.0 & 2.0 \\
\hline$\left[(2 \mathrm{~S}, 3 \mathrm{~S}) \mathrm{MePhe}^{3}\right] \mathrm{JOM}-13$ & 259 & 1.52 & 0.0 & 2.2 & 1.5 \\
\hline$\left[(2 \mathrm{R}, 3 \mathrm{~S}) \mathrm{MePhe}^{3}\right] \mathrm{JOM}-13$ & $>10,000$ & 237 & 4.7 & 0.0 & 1.2 \\
\hline$\left[(2 \mathrm{R}, 3 \mathrm{R}) \mathrm{MePhe}^{3}\right] \mathrm{JOM}-13$ & $>10,000$ & 4.80 & 6.3 & 6.1 & 0.0 \\
\hline
\end{tabular}
Containing Analogues ${ }^{a}$

\footnotetext{
${ }^{a}$ Binding affinities at $\mu$ and $\delta$ receptors were determined by displacement of $\left[{ }^{3} \mathrm{H}\right] \mathrm{DAMGO}$ ([D-Ala ${ }^{2}, \mathrm{NMePhe}^{4}, \mathrm{Gly}^{5}$-ol] $]$ enkephalin) and $\left[{ }^{3} \mathrm{H}\right]$ DPDPE, respectively. ${ }^{18}$
} 

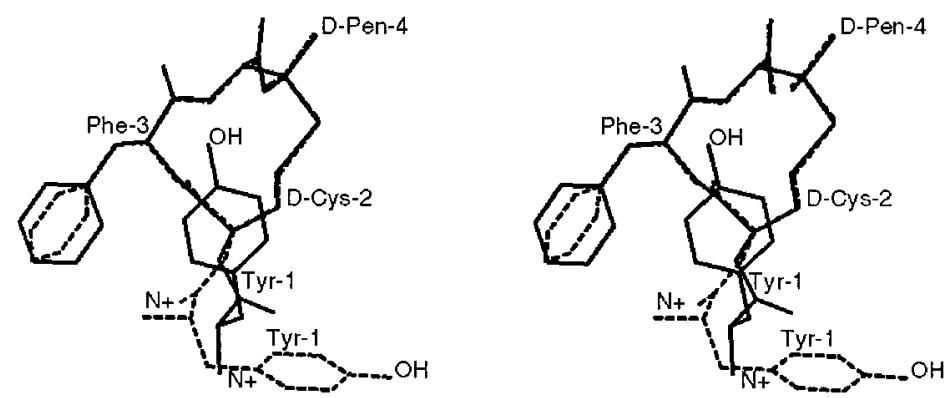

FIGURE 5 Proposed (solid line) and "alternate" (dashed line) bioactive conformations of JOM-13.

for JOM-13 and related analogues to be proposed. This "proposed" conformation, with $\varphi^{2} \sim 160^{\circ}$, and the alternate conformer with $\varphi^{2} \sim 70^{\circ}$ (see discussion above) are shown in Figure 5.

Although we had at this time proposed a bioactive conformation of JOM-13, the choice of the $\varphi^{2}$ $\sim 160^{\circ}$ conformer rather than the $\varphi^{2} \sim 70^{\circ}$ conformer was based solely on the better superposition of high affinity and moderate affinity JOM-13 analogues in the former case. Consequently, we were interested in comparing both conformations with those of other conformationally constrained $\delta$ ligands. Among the ligands chosen for comparison were the relatively rigid alkaloids 7-spiroindanyloxymorphone (SIOM), a $\delta$ selective agonist, ${ }^{20}$ and oxymorphindole (OMI), a $\delta$ selective antagonist. ${ }^{21}$ As shown in Figure 6, the proposed ("preferred") JOM-13 binding conformer superimposes well with both alkaloid ligands. ${ }^{22}$ In all cases the tyramine regions of the ligands are similarly arranged, while the second aromatic rings (the Phe side chain of JOM-13 and the indanyl and indole moieties of SIOM and OMI, respectively) occupy similar spatial positions. It was further observed that these second aromatic rings were coplanar in the agonists JOM-13 and SIOM, but tilted in OMI, leading to the suggestion that orientation of this aromatic ring distinguishes agonist from antagonist binding. ${ }^{22}$ In Figure 7, superposition of SIOM and OMI with JOM-13 in its alternate conformer (from Figure 5) is shown. This superposition clearly does not allow simultaneous correspondence of the tyramine and second aromatic regions. Therefore, we concluded that the preferred JOM-13 binding conformer was indeed correct and that even structurally diverse $\delta$ ligands (and indeed, even agonists and antagonists) bind very similarly. Of course, this supposition that different ligands bind in a similar manner, while comforting to those trying to interpret structureactivity data in the absence of receptor structural information, is not necessarily correct. Indeed, it has been demonstrated that even structurally quite similar ligands may bind to their common macromolecular target in quite different ways. ${ }^{23}$ Thus, although structure-activity and conformation-activity studies of ligands are very informative, they are insufficient, by themselves, for confident deductions of how these ligands interact with their receptors. Of course, an experimental structure for the ligand-receptor complex would be the ideal, but lacking this, an approach that allows the construction of reliable high resolution structural models of the receptor can fill this gap.
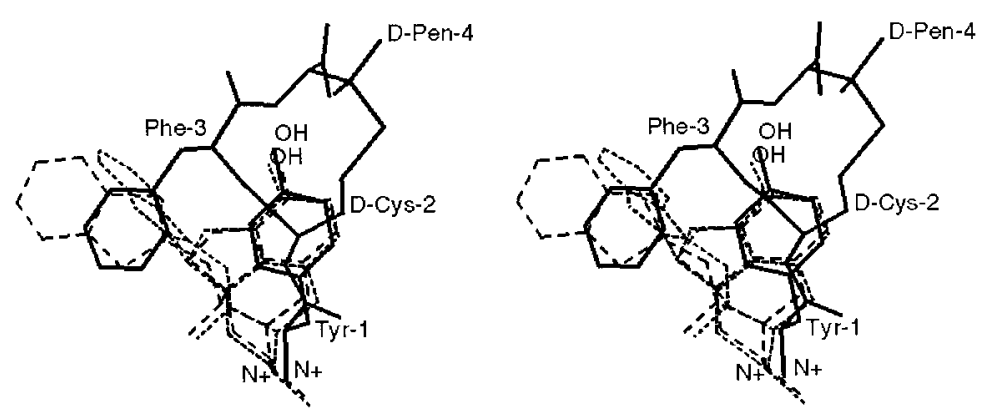

FIGURE 6 Superposition of JOM-13 (proposed bioactive conformer, solid line), SIOM (dashed line), and OMI (dotted line). 

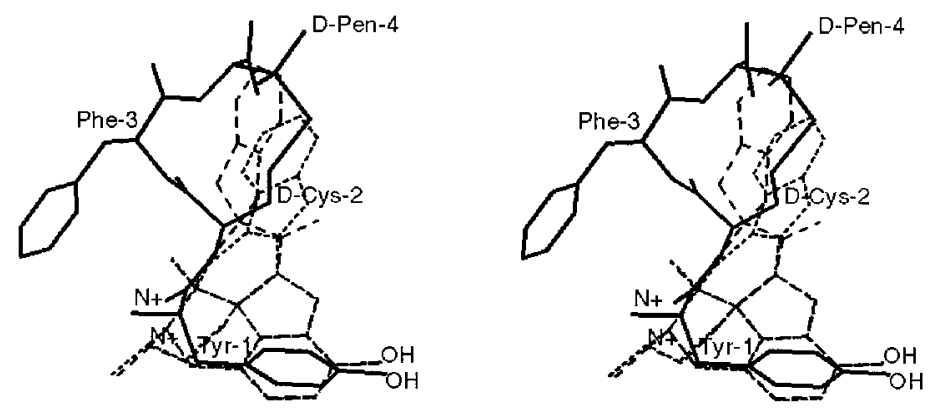

FIGURE 7 Superposition of JOM-13 (alternate bioactive conformer, solid line), SIOM (dashed line), and OMI (dotted line).

\section{DEVELOPMENT OF A NEW APPROACH FOR MODELING G PROTEIN-COUPLED RECEPTORS}

As depicted in Figure 8 for the $\delta$ opioid receptor, GPCRs contain 7 transmembrane helices (TMH) connected by three intracellular (IL) and three extracellular (EL) loops. An additional intracellular loop, IL-4, connects the C-terminal end of TMH VII to a highly conserved palmitoylated cysteine in GPCRs. The intra- and extracellular GPCR domains are critical to receptor function. The extracellular loops of many GPCRs, including opioid receptors, are involved in ligand binding (see, for example, Ref. 24), while the intracellular loops and $\mathrm{C}$-terminal region interact with G-proteins, protein kinases, arrestins, and other molecules involved in downstream events of the transduction pathway. ${ }^{25-27}$

EM studies of several rhodopsins ${ }^{4-6}$ have provided low resolution ( $\sim 5-7 \AA$ in the plane of the membrane, much lower resolution perpendicular to the membrane plane) structural data that clearly show these receptors to contain the seven transmembrane $\alpha$-helices depicted in Figure 8. Furthermore, the presence, in each transmembrane helix, of several characteristic residues conserved throughout the rhodopsin-like GPCRs indicates that all proteins in the family share a common three-dimensional (3D) structure. ${ }^{28}$ The existence of a minimum sequence homology of $\sim 20 \%$ between remotely related GPCRs suggests a $\sim 1.6-2.3 \AA$ rms deviation (RMSD) of mainchain atoms within the $\alpha$-helical core, using a

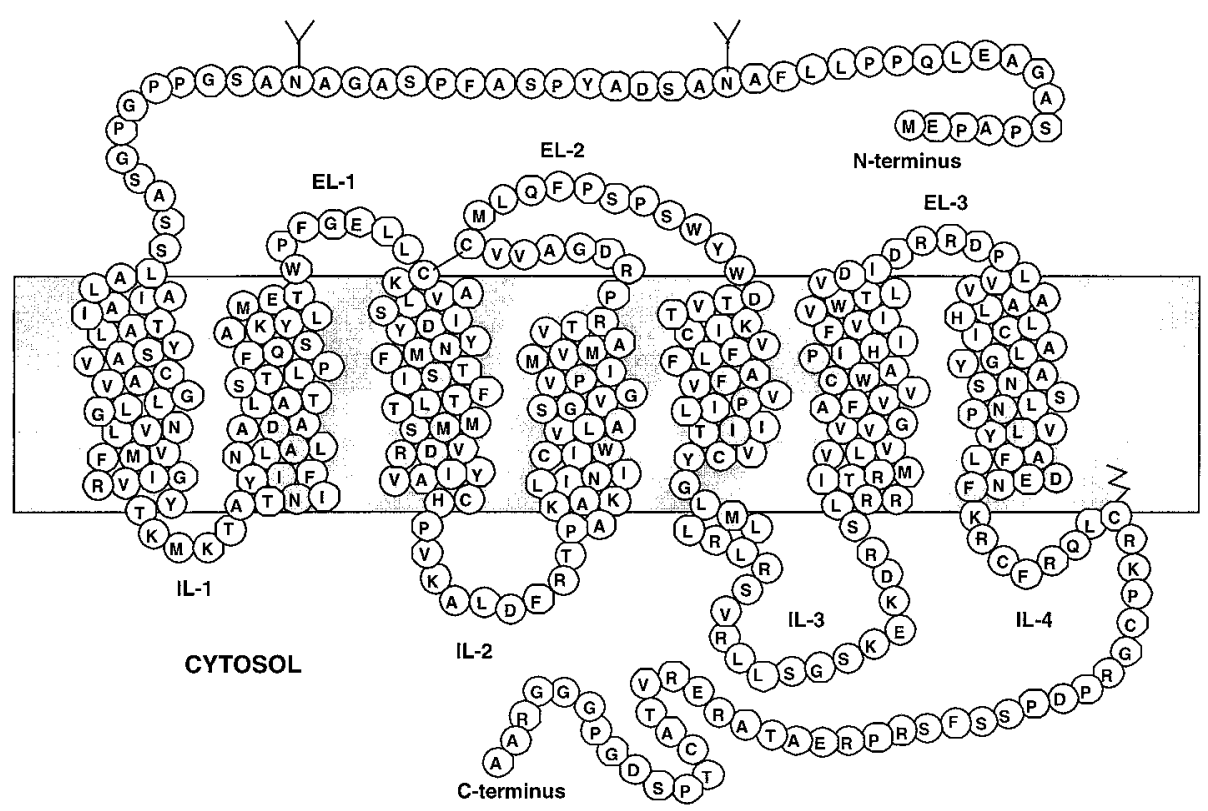

FIGURE 8 Serpentine model of the $\delta$ opioid receptor. Shaded residues are those highly conserved within the rhodopsin-like family of GPCRs. 
calibration curve relating the coordinate RMSD and sequence identity for proteins with known 3D structures. $^{29}$

GPCRs, especially rhodopsin itself, have been extensively studied by site-directed mutagenesis and by a variety of physicochemical methods. These experimental data and the analysis of variability and hydrophobicity patterns in amino acid sequences of GPCRs allow the identification within the GPCR primary sequence of the transmembrane helices and their unequivocal assignment to the peaks in the EM maps, ${ }^{28}$ and from this assignment, the construction of various approximate GPCR models. Modeling of the transmembrane domain is simplified by the identification of residues that are evolutionarily conserved or hydrophilic, or that are important for folding or ligand binding. These residues form the protein interior, thus defining a lipid-inaccessible surface of each transmembrane helix and placing a restriction on rotational orientation of the helix and the depth of its immersion into the $\alpha$-bundle. ${ }^{28,30,31}$ GPCR models typically have been built from seven "ideal" helices with arbitrarily chosen side-chain conformers (or without side chains at all) to satisfy the EM maps, the restrictions on rotational orientations of the helices, and constraints derived from mutagenesis and cross-linking data. ${ }^{32-37}$ Such models are helpful for suggesting mutagenesis studies, but are insufficiently precise to provide accurate details of ligand-receptor recognition. During the past few years we have developed a more precise structure of the transmembrane $\alpha$-bundle based upon the observation that numerous polar residues are present within the transmembrane, hydrophobic $\alpha$-helices of GPCRs. It is known that water-inaccessible, polar side chains of proteins have a strong tendency to form $\mathrm{H}$ bonds. ${ }^{38}$ In transmembrane $\alpha$-helices, backbone peptide groups are already paired (except for the carbonyl "partners" of proline residues); hence, the polar side chains must interact with each other to form intra- or interhelical $\mathrm{H}$ bonds. If these $\mathrm{H}$ bonds can be identified, then they can be used for refinement of a crude $\alpha$-bundle model (based upon the EM maps, as described above) by distance geometry calculations, much like nmr-derived experimental protein structures. The candidate $\mathrm{H}$ bonds indeed can be identified from the analysis of sequence alignments as polar residues, in intramembrane segments, which appear and disappear simultaneously in various GPCRs, i.e., residues whose presence throughout the many GPCR sequences is highly pairwise correlated. Such pairwise correlation suggests spatial proximity, which for polar residues in a nonpolar environment connotes an $\mathrm{H}$-bond interaction. We had originally envisioned applying this procedure to an individual receptor se- quence; however, it soon became clear that any single GPCR has too few H-bonding constraints to lead to a convergent structure. This obstacle was surmounted by reasoning that, since the structure of the $\alpha$-bundle for all GPCRs must be very similar, the side-chain H-bonds from many different GPCRs can be combined to increase the number of constraints. Accordingly, our initial receptor sequence (bovine rhodopsin) was "virtually mutated" to incorporate pairwise correlated polar residues present in other GPCRs. This "composite" receptor was then used to calculate, via the distance geometry algorithm, an "average" 7 - $\alpha$-bundle structure. The computational procedure employed, which we have described in detail elsewhere, ${ }^{7}$ was organized as an iterative refinement with evolving constraints. Examination of structures during the iterative procedure led to the identification of additional $\mathrm{H}$-bond constraints (and to the identification and elimination of "false positives"), which were then included in subsequent iterations. The iterative procedure began with the initial "crude" model of the $\alpha$-bundle and continued until every buried polar side chain from each of the 410 GPCRs considered (collectively, $>20,000$ side chains) was able to participate in at least one hydrogen bond in the final structure. This "saturation of H-bonding potential" criterion was very sensitive to errors during the refinement. Although the transmembrane segments of individual GPCRs are hydrophobic and contain less than 30\% polar residues, when 410 different amino acid sequences are simultaneously considered, all interhelical contacts within the $\alpha$-bundle are "labeled" by polar side chains forming intramolecular $\mathrm{H}$ bonds, usually in a group of related receptors. Displacement of $\alpha$-helices from their correct positions breaks some $\mathrm{H}$ bonds, producing unpaired polar side chains within the lipid bilayer in tens or hundreds of GPCRs.

Although the 7- $\alpha$ bundles of all rhodopsin-family GPCRs can be expected to be structurally similar, they are unlikely to be identical. Further, due to the incorporation of constraints from many GPCRs in the calculation of the "average" model, it is likely that this model is overconstrained. Hence, the calculation of a specific receptor model, using the same iterative distance geometry approach, utilizes only those hydrogen-bonding constraints applicable to that receptor, while using the average model to constrain the positions of the helices, but allowing $\sim 1.0 \AA$ deviations from the imposed interhelical constraints to allow the $\alpha$ bundle to "relax." The resulting specific receptor models demonstrate excellent packing and polarity matching, have all side chains in Ramachandran-allowed conformations, and are in excellent agreement with available experimental data. ${ }^{7,8,39}$ 
A number of additional observations further support the validity of our calculated 7- $\alpha$ bundle structures:

1. Close packing of nonpolar side chains and correlated replacements. In comparisons of distinctly different GPCRs (sequence identity 20 $25 \%$ ), many examples of correlated replacements throughout the transmembrane domain are observed. The appearance of a bulky (especially aromatic) side chain in one receptor (in place of a smaller side chain in another receptor) is usually accompanied by a concomitant decrease of volume in several surrounding side chains to maintain good packing of the structure. $^{7}$

2. Clustering of conserved residues. Forty evolutionarily conserved GPCR residues form a single continuous domain in the intracellular region of the 7- $\alpha$ bundle. This domain is composed of a large aliphatic cluster and six smaller clusters of polar and aromatic side chains, similar to the clustering of conserved residues observed in proteins with known 3D structures. ${ }^{40}$

3. Clustering of residues with similar polarities. In the calculated GPCR models, all polar and nonpolar residues are segregated into clusters of similar polarity. Moreover, the side chains of different polarity tend to be organized as in a "polarity gradient" with the most polar groups (from Asp, Asn, Glu, Gln, Lys, etc., residues) separated from the least polar aliphatic groups by aromatic and sulfur-containing groups of intermediate polarity. ${ }^{7}$ Such an arrangement can be expected to be energetically favorable.

\section{Opioid Receptor Models}

Models for the 7- $\alpha$ bundles of the $\delta, \mu$, and $\kappa$ opioid receptors were constructed using the approach described above. However, although the ligand binding pocket consists mainly of residues from the transmembrane $\alpha$-bundle, the extracellular loops of opioid receptors have also been shown to be important for interactions with many ligands. ${ }^{41-45}$ Hence, loop modeling, using a modified version of the distance geometry refinement used for calculation of the transmembrane $\alpha$-bundle, was also initiated. ${ }^{8}$ The short (5-7 residues, Figure 8) EL-1 and EL-3 segments can be viewed as merely linking TMHs; however the longer EL-2 (20 residues in the $\delta$ receptor) partially covers the binding cavity between helices III-VII in the transmembrane $\alpha$-bundle model and can interact directly with opioid ligands.
Modeling of EL-2 presents additional difficulties compared with the transmembrane domains, since specific secondary structure cannot be assumed. However, this loop is constrained by the attachment of its ends to the tops of TMH IV and V and its additional covalent attachment, via a disulfide, to the end of TMH III (Figure 8), giving this loop a U-like shape. Both branches of this " $U$ " are too short to form any additional $\alpha$-helices in the calculated models of the transmembrane domain, and the geometrical constraints imposed by their attachment to TMH III, IV, and $\mathrm{V}$ forces them to adopt extended structures. Examination of the sequence patterns in this loop for all three opioid receptors suggests that the two extended antiparallel stretches of EL-2 near the conserved disulfide bond are paired in a $\beta$-hairpin, while the remainder of EL-2, connecting the $\beta$-hairpin to helices IV and V, adopts nonregular structure. Further details of the proposed conformation of EL-2 are presented elsewhere. $^{8}$

Our $\delta$ (and $\mu$ and $\kappa$ ) opioid receptor model has a large cavity in the extracellular side of the transmembrane bundle between helices III-VII that is partially covered by the $\beta$-hairpin formed by EL-2. This cavity, which defines the binding pocket, is formed mainly by nonpolar residues but contains several polar residues as well $\left(\mathrm{Asp}^{128}, \mathrm{Tyr}^{129}, \mathrm{Asp}^{210}, \mathrm{Lys}^{214}, \mathrm{His}^{278}\right)$. Some side chains oriented toward the cavity appear to be flexible. Side-chain reorientation of $\mathrm{Leu}^{125}\left(\chi^{1}\right.$ $=-60^{\circ}, \chi^{2}=180^{\circ}$; or $\left.\chi^{1}=180^{\circ}, \chi^{2}=60^{\circ}\right), \mathrm{Asp}^{128}$ $\left(\chi^{1}=-60^{\circ}\right.$ or $\left.180^{\circ}\right), \operatorname{Tyr}^{129}\left(\chi^{1}=-60^{\circ}\right.$ or $\left.180^{\circ}\right)$, $\operatorname{Asp}^{210}\left(\chi^{1}=180^{\circ}\right.$ or $\left.\pm 60^{\circ}\right), \operatorname{Lys}^{214}\left(\chi^{1}=180^{\circ}\right.$ or $-60^{\circ}, \chi^{2}-\chi^{4}=180^{\circ}$ or $\left.\pm 60^{\circ}\right), \mathrm{Leu}^{300}\left(\chi^{1}=-60^{\circ}\right.$, $\chi^{2}=180^{\circ}$; or $\left.\chi^{1}=180^{\circ}, \chi^{2}=60^{\circ}\right)$, or $\operatorname{Trp}^{284}\left(\chi^{2}\right.$ $\left.= \pm 90^{\circ}\right)$ during distance geometry calculations does not affect the scoring functions or the overall calculated structures (RMSD) for all $\mathrm{C}^{\alpha}$ atoms $<0.5 \AA$ ) but does change the shape of the binding pocket. The flexibility of these residues allows their adjustment during ligand fitting. Indeed, the docking of different ligands requires the rotation of some of these residues to avoid steric hindrances. ${ }^{8}$

The 36 residues of the $\delta$ receptor in the vicinity of JOM-13 (proximity of $6 \AA$ ) are shown in Figure 9. Many of these residues are conserved in $\delta, \mu$, and $\kappa$ opioid receptors and interact with the common tyramine feature of opioid ligands, while other residues are variable and may account for selective receptorligand interactions. The "variable region" consists mostly of residues from the ends of the transmembrane helices and from the extracellular loops. Docking of opioid ligands was directed by positioning their common tyramine moiety on the bottom of cavity with the protonated amine oriented toward Asp ${ }^{128}$ 

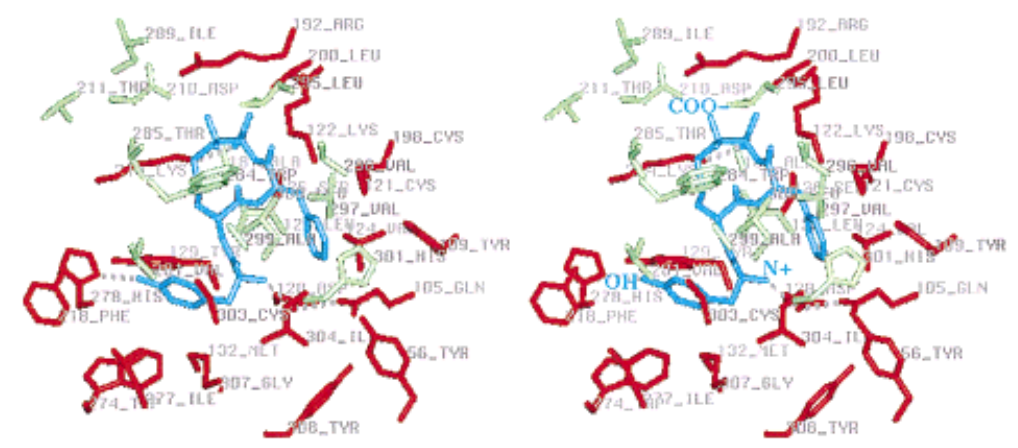

FIGURE 9 JOM-13 (blue) in the $\delta$ opioid receptor binding pocket (stereoview). Conserved and variable (in $\mu, \delta$, and $\kappa$ receptors) receptor residues are denoted by red and green, respectively.

(TMH III) and the hydroxyl group oriented toward His $^{278}$ (TMH VI). The importance of these ligand functional groups and the corresponding receptor residues has been convincingly implicated by mutagenesis and ligand structure-activity studies. The rest of the tyramine moiety was positioned in the cavity to fill the empty space and to avoid steric hindrances. JOM-13 was positioned in the $\delta$ receptor binding pocket using the experimental crystal structure of this peptide's 11-membered cycle, but with adjusted torsion angles for the exocyclic $\mathrm{Tyr}^{1}$ residue and $\chi^{1}$ angle of $\mathrm{Phe}^{3}$. This positioning can only be done in the trans $\left(\chi^{1} \sim 180^{\circ}\right)$ orientation of the $\mathrm{Tyr}^{1}$ side chain, in agreement with our structure-activity results for $\mathrm{X}^{1}$-JOM-13 analogues, described above. Next, the gauche $^{+}\left(\chi^{1}=-60^{\circ}\right)$ orientation of $\mathrm{Phe}^{3}$ was chosen based on the residue 3 structure-activity results for JOM-13 analogues. ${ }^{18,19}$ Then, the spatial position of the disulfide-bridged, 11-membered ring relative to the fixed $\mathrm{Tyr}^{1}$ was adjusted by rotating torsion angles $\psi^{1}$ (of $\mathrm{Tyr}^{1}$ ) and $\varphi^{2}$ (of D-Cys ${ }^{2}$ ). As described above, two alternative conformers of JOM-13, with $\varphi$ angle of $\mathrm{D}-\mathrm{Cys}^{2} \sim 160^{\circ}$ or $\sim 70^{\circ}$ were found to be energetically plausible and consistent with structure-activity data. Of these, the $\varphi^{2} \sim 160^{\circ}$ conformer was proposed to be the binding conformation since it provided a better superposition of all pharmacophoric elements $\left(\mathrm{Tyr}^{1}\right.$ residue and $\mathrm{Phe}^{3}$ side chain) in different analogues of JOM-13. ${ }^{17,18}$ However, ligand-receptor docking of JOM-13 clearly shows that only the alternate, $\varphi^{2} \sim 70^{\circ}$, conformer can fit the binding pocket. Indeed, the receptor models show that a precise superposition of all pharmacophoric elements in different ligands is not required and that, even in similar cyclic peptides, the functionally important phenylalanine aromatic ring may slightly change orientation and location. This is discussed in further detail elsewhere. $^{8}$

The bound conformation of JOM-13 geometrically fits the binding pocket of the $\delta$-receptor and forms a number of complex-stabilizing H-bonds and hydrophobic contacts with surrounding receptor residues (Figure 9). The binding pocket can be considered to be composed of subsites that are complementary to individual structural elements of JOM-13, i.e., its $\mathrm{Tyr}^{1}$ residue, $\mathrm{Phe}^{3}$ side chain, and $\mathrm{C}$-terminal $\mathrm{COO}^{-}$ group.

\section{Tyr $^{1}$ Subsite}

The positively charged nitrogen of $\mathrm{Tyr}^{1}$ of JOM-13 participates in an ionic interaction with the side chain carboxyl of $\mathrm{Asp}^{128}$ (TMH III) and is surrounded by polar residues from TMH I $\left(\mathrm{Tyr}^{56}\right)$, TMH II $\left(\mathrm{Gln}^{105}\right)$, and TMH VII (His ${ }^{301}$ and $\mathrm{Tyr}^{308}$ ) (Figure 10). The $\mathrm{O}^{\eta}$ group of $\mathrm{Tyr}^{1}$ forms an $\mathrm{H}$ bond with $\mathrm{N}^{\delta}$ of $\mathrm{His}^{278}$ (TMH VI). The aromatic ring of $\operatorname{Tyr}^{1}$ occupies the bottom of the cavity between TMH III, TMH V, and TMH VI and interacts with sulfur-containing (Met ${ }^{132}$, $\left.\mathrm{Cys}^{303}\right)$, aromatic $\left(\mathrm{Tyr}^{129}, \mathrm{Phe}^{218}, \operatorname{Trp}^{274}\right)$, and aliphatic $\left(\mathrm{Leu}^{125}, \mathrm{Il}^{277}, \mathrm{Val}^{281}, \mathrm{Il}^{304}\right)$ residues. There are a few empty regions around $\mathrm{Tyr}^{1}$ in the cavity, suggesting that $\mathrm{Tyr}^{1}$ of JOM-13 may have residual flexibility inside the pocket, with the aromatic ring occupying essentially the same spatial position for different combination of $\psi^{1}$ and $\varphi^{2}$ angles. The side chain of $\mathrm{Tyr}^{129}$ (TMH III) also retains flexibility and can assume trans $\left(\chi^{1}=180^{\circ}\right)$ or gauche $\left(\chi^{1}=-60^{\circ}\right)$ rotamers without substantial steric hindrance with the ligand. In the latter case, $\mathrm{Tyr}^{129}$ can form an H-bond with the backbone carbonyl of the Tyr residue of JOM-13 (not shown). The unoccupied space around $\mathrm{Tyr}^{1}$ allows the binding site to accommodate methyl groups in the $2^{\prime}$ and $6^{\prime}$ position of $\mathrm{Tyr}^{1}$ or the extra ring of $\mathrm{Hpp}^{1}$, consistent with the high affinity observed for the corresponding JOM-13 analogues. ${ }^{17}$ On the other hand, the $\mathrm{C}^{\alpha} \mathrm{H}$ atom of $\mathrm{Tyr}^{1}$ is in close contact with Leu ${ }^{125}$ or $\operatorname{Tyr}^{129}$ (for $\chi^{1}=-60^{\circ}$ ) and an additional $\mathrm{C}^{\alpha}$-methyl group incorporated here would 


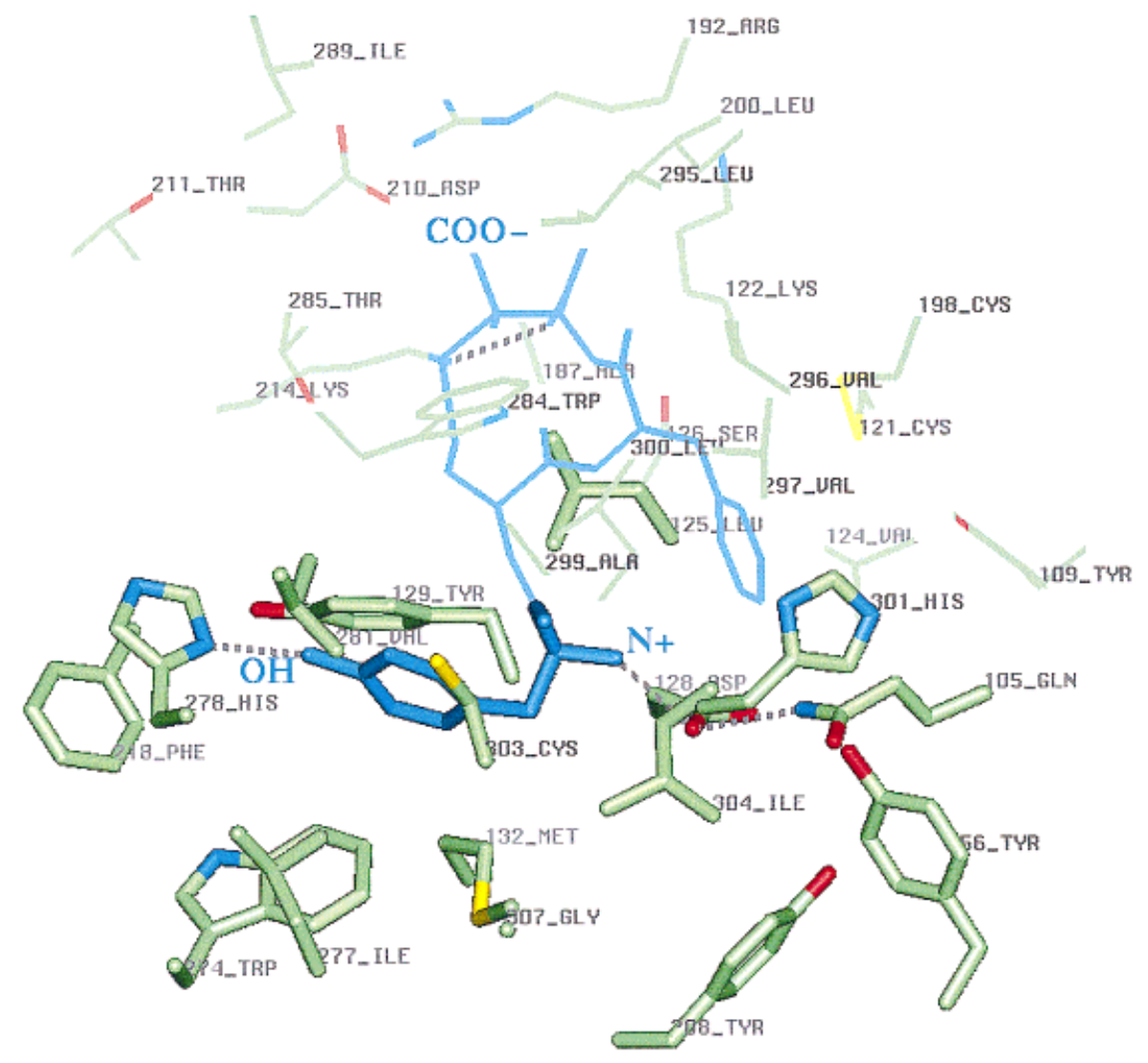

FIGURE 10 JOM-13 (blue) in the $\delta$ opioid receptor binding pocket. The ligand's Tyr residue and the corresponding receptor subsite residues are should in the "licorice" representation.

experience steric hindrance with the side chain of $\mathrm{Leu}^{125}$ or the aromatic ring of $\mathrm{Tyr}^{129}$, consistent with the decreased affinities of $\mathrm{C}^{\alpha} \mathrm{MeTyr}^{1}$, $\mathrm{Hai}^{1}$, and $\mathrm{Hat}^{1}$ analogues of JOM-13. ${ }^{17}$ The proximity between the first peptide group of the ligand and the Leu ${ }^{125}$ side chain precludes the accommodation of $\mathrm{N}^{\alpha}$ substitutions in residue 2 of the ligand. This is consistent with the low affinity of [NMe-D-Cys $\left.{ }^{2}\right] \mathrm{JOM}-13 .{ }^{46}$ Replacements of $\mathrm{Tyr}^{1}$ by D-Tyr ${ }^{1}$ and HO-Tic ${ }^{1}(1,2,3,4$,-tetrahydro-7-hydroxyisoquinoline-3-carboxylic acid) residues, which have entirely different orientations of the tyrosine ring within the pocket, produce numerous overlaps with surrounding receptor atoms, consistent with the observed low binding affinities of $\mathrm{D}-\mathrm{Tyr}^{1}$ and HO-Tic ${ }^{1}$ analogues of JOM-13 (Ref. 17, and unpublished observations).

\section{Phe ${ }^{3}$ Subsite}

The Phe $\mathrm{P}^{3}$ side chain of JOM-13 $\left(\chi^{1}=-60^{\circ}\right)$ is positioned on the side of the cavity between helices II, III, and VII. The aromatic ring of $\mathrm{Phe}^{3}$ is located below the conserved $\mathrm{Cys}^{121}$ - $\mathrm{Cys}^{198}$ disulfide bond and also interacts with residues from TMH II $\left(\mathrm{Gln}^{105}\right.$, $\mathrm{Tyr}^{109}$ ), TMH III $\left(\mathrm{Val}^{124}\right.$, Leu ${ }^{125}$ ), and TMH VII $\left(\mathrm{Val}^{297}, \mathrm{Leu}^{300}, \mathrm{His}^{301}\right.$, and $\mathrm{Il}^{304}$ ) (see Figure 11). The presence of significant empty space in this region of the binding cavity could allow a reorientation of the $\mathrm{Phe}^{3}$ side chain from $\chi^{1}=-60^{\circ}$ to $\chi^{1}=180^{\circ}$. In this case, the aromatic ring of $\mathrm{Phe}^{3}$ would occupy an alternate position, above the disulfide bond, and would interact primarily with residues from EL-2 $\left(\mathrm{Leu}^{200}, \mathrm{Cys}^{198}\right), \mathrm{EL}-3\left(\mathrm{Leu}^{295}\right)$ and the extracellular terminus of TMH III (Cys ${ }^{121}$, Lys ${ }^{122}$ ). However, in our model, this would create steric hindrance between $\mathrm{Phe}^{3}$ of the peptide and surrounding residues of the receptor. Therefore, the preferred orientation of $\mathrm{Phe}^{3}$ in the $\delta$ receptor model is gauche $\left(\chi^{1}=-60^{\circ}\right)$, in agreement with the high affinities of $\left[\Delta^{\mathrm{z}} \mathrm{Phe}^{3}\right]$ and $\left[(2 \mathrm{~S}, 3 \mathrm{~S}) \mathrm{MePhe}^{3}\right]$ analogues of JOM-13, ${ }^{18,19}$ in which the $\chi^{1}$ angles of residue 3 are fixed in this orientation. The reduced $\delta$ binding affinity observed for $\left[\Delta^{\mathrm{E}} \mathrm{Phe}^{3}\right] \mathrm{JOM}-13$, where $\chi^{1}$ of $\mathrm{Phe}^{3}$ is fixed at $180^{\circ},{ }^{19}$ is also consistent with the model. The size of the cavity in the $\mathrm{Phe}^{3}$ subsite is large enough to accommodate even bulkier side chains, such as those of $\mathrm{Nal}^{3}$ 


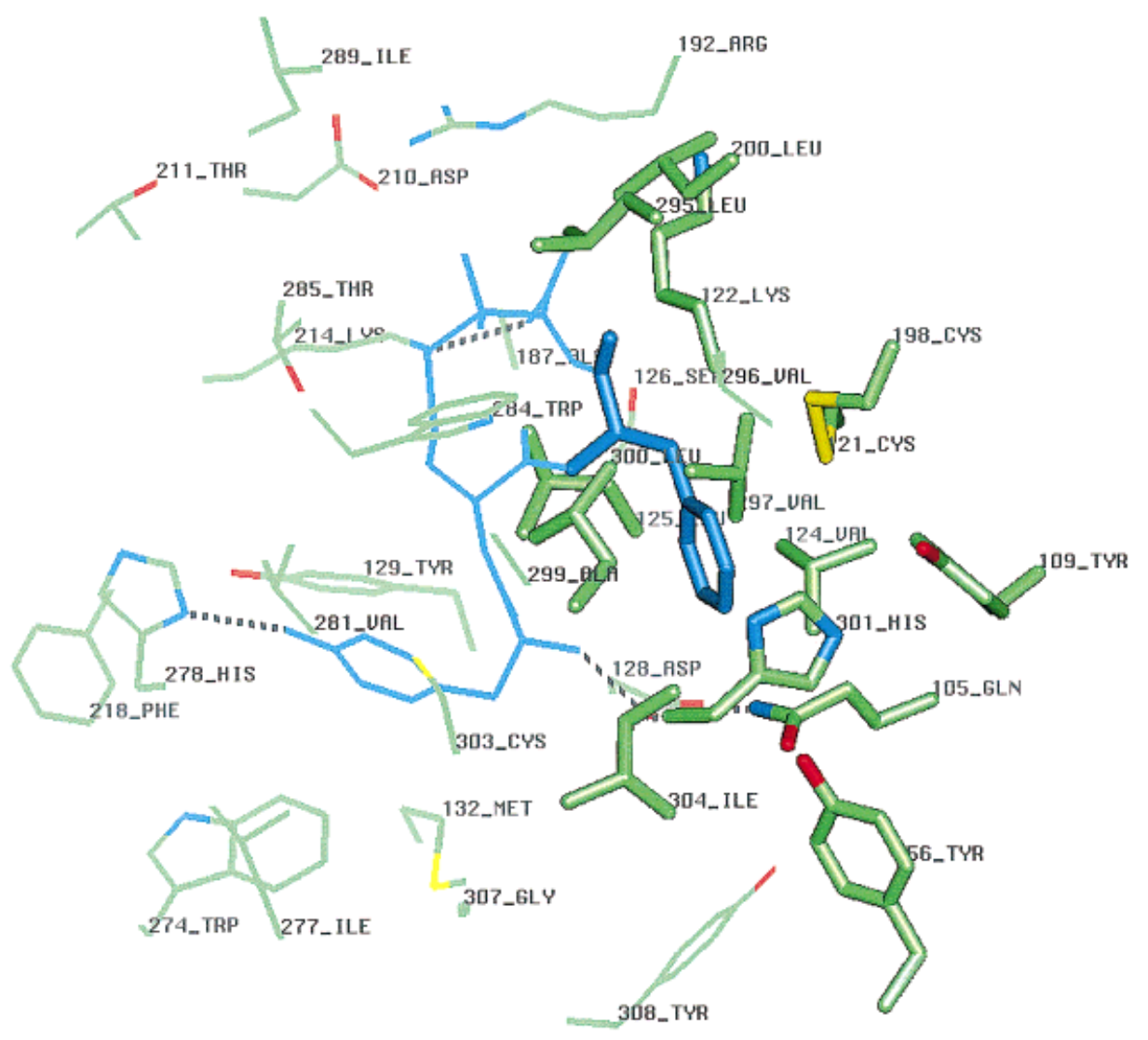

FIGURE 11 JOM-13 (blue) in the $\delta$ opioid receptor binding pocket. The ligand's Phe residue and the corresponding receptor subsite residues are should in the licorice representation.

(naphthylalanine) or $\operatorname{Trp}^{3}$ in the same $\chi^{1}=-60^{\circ}$ orientation, consistent with the high affinity of the corresponding analogues of JOM-13. ${ }^{47}$

\section{$\mathrm{COO}^{-}$Subsite}

The C-terminal $\mathrm{COO}^{-}$group of JOM-13 forms an ionic interaction with the $\varepsilon$ amine of $\mathrm{Lys}^{214}\left(\chi^{1}\right.$ $=-60^{\circ}, \chi^{2}-\chi^{4}=180^{\circ}$ ) buried inside the $\alpha$-bundle (Figure 12). This ionic interaction between these oppositely charged groups is lacking for carboxamide terminal peptide ligands, such as the carboxamide analogue of JOM-13, which displays a 10-fold reduction in $\delta$ binding affinity. ${ }^{15}$ A terminal carboxamide does, however, improve binding to $\mu$ receptors, consistent with the well established observation that negatively charged groups in this region of the ligand (either C-terminal in tetrapeptide and pentapeptide opioids or residue 4 side chains in deltorphins) hamper binding to this receptor. Interestingly, Lys ${ }^{214}$ of the $\delta$ receptor is conserved in $\mu$ (and $\kappa$ ) receptors, however $\mathrm{Asp}^{210}$ is replaced by Glu in the $\mu$ receptor. Further, our models suggest that peptide ligands are slightly shifted in the $\mu$ binding site relative to the $\delta$ binding site. Together these factors result in an adverse electrostatic interaction between the negative charges of the ligand and this Glu side chain, consistent with the observed poor $\mu$ receptor binding affinity of such ligands.

In summary, we have demonstrated that our ligand pharmacophore model of JOM-13, developed from conformation-activity analysis of this ligand and a series of further conformationally constrained analogues, provides an excellent fit to the binding pocket of our $\delta$ opioid receptor model, constructed without any ligand structure bias. The observation that, of the two possible ligand bioactive conformations proposed from study of the ligand alone, only the "alternate" conformer, which provides much less satisfactory overlap with other conformationally restricted $\delta$ ligands, can be accommodated, reflects the fact that some subsites of the binding pocket have sufficient space and conformational variability to adjust to different orientations of pharmacophore elements common among different ligands. Thus, the requisite tyramine moiety of opioid ligands interacts similarly at 


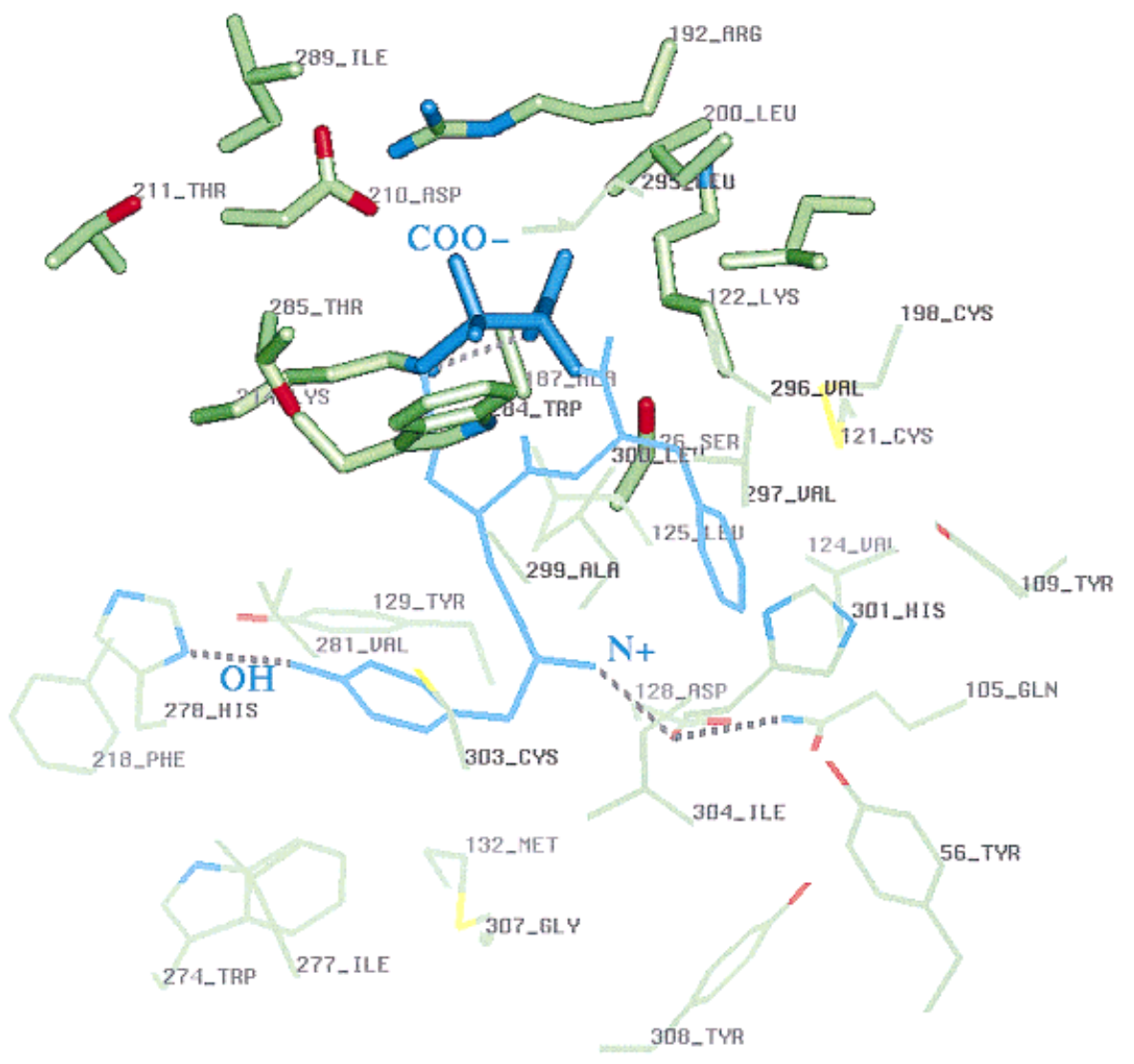

FIGURE 12 JOM-13 (blue) in the $\delta$ opioid receptor binding pocket. The ligand's Pen residue and the corresponding receptor subsite residues are should in the licorice representation.

the $\delta$ receptor, while the binding subsite of the second aromatic ring arising from the $\mathrm{Phe}^{3}$ or $\mathrm{Phe}^{4}$ residue of opioid peptides or the indole and indanyl moieties of OMI and SIOM, respectively, allows more variability in the ligand. The fact that an incorrect choice of the bioactive conformation of JOM-13 would be made based only on the ligand studies underscores, of course, the value of complementary receptor modeling.

The author is very grateful to Irina Pogozheva and Andrei Lomize for their generous assistance with this manuscript. The studies described were supported by grants DA03910, DA09989, and DA00118 from the National Institutes of Health.

\section{REFERENCES}

1. Wlodawer, A.; Vondrasek, J. Annu Rev Biophys Biomol Struct 1998, 27, 249-284.

2. Wallin, E.; Von Heijne, G. Protein Sci 1998, 7, 1029_ 1038.
3. Watson, S.; Arkinstall, S. The G-Protein Linked Receptor Facts Book; Academic Press: San Diego, 1994.

4. Unger, V. M.; Schertler, G. F. X. Biophys J 1995, 68, 1776-1786.

5. Unger, V. M.; Hargrave, P. A.; Baldwin, J. M.; Schertler, G. F. X. Nature 1997, 389, 203-211.

6. Davies, A.; Schertler, G. F. X.; Gowen, B. E.; Saibil, H. R. J Structur Biol 1996, 117, 36-44.

7. Pogozheva, I. D.; Lomize, A. L.; Mosberg, H. I. Biophys J 1997, 70, 1963-1985.

8. Pogozheva, I. D.; Lomize, A. L.; Mosberg, H. I. Biophys J 1998, 75, 612-634.

9. Mosberg, H. I.; Hurst, R.; Hruby, V. J.; Gee, K.; Yamamura, H. I.; Galligan, J. J.; Burks, T. F. Proc Natl Acad Sci 1983, 80, 5871-5874.

10. Mosberg, H. I.; Sobczyk-Kojiro, K.; Subramanian, P.; Crippen, G. M.; Ramalingam, K.; Woodard, R. W. J Amer Chem Soc 1990, 112, 822-829.

11. Hruby, V. J.; Kao, L.-F.; Pettit, B. M.; Karplus, M. J Amer Chem Soc 1988, 110, 3351-3359.

12. Pettitt, B. M.; Matsunaga, T.; Al-Obeidi, F.; Gehrig, C.; Hruby, V. J.; Karplus, M. Biophys J 1991, 60, $1540-$ 1544.

13. Froimowitz, M. Biopolymers 1990, 30, 1011-1025. 
14. Chew, C.; Villar, H.; Loew, G. Mol Pharmacol 1991, $39,502-510$.

15. Mosberg, H. I.; Omnaas, J. R.; Smith, C. B.; Medzihradsky, F. Life Sciences 1988, 43, 1013-1020.

16. Lomize, A. L.; Flippen-Anderson, J. L.; George, C.; Mosberg, H. I. J Amer Chem Soc 1994, 116, 429-436.

17. Mosberg, H. I.; Lomize, A. L.; Wang, C.; Kroona, H.; Heyl, D. L.; Sobczyk-Kojiro, K.; Ma, W.; Mousigian, C.; Porreca, F. J Med Chem 1994, 37, 4371-4383.

18. Mosberg, H. I.; Omnaas, J. R.; Lomize, A.; Heyl, D. L.; Nordan, I.; Mousigian, C.; Davis, P.; Porreca, F. J Med Chem 1994, 37, 4384-4391.

19. Mosberg, H. I.; Dua, R. K.; Pogozheva, I. D.; Lomize, A. L. Biopolymers 1996, 39, 287-296.

20. Portoghese, P. S.; Moe, S. T.; Takemori, A. E. J Med Chem 1993, 36, 2572-2574.

21. Portoghese, P. S.; Sultana, M.; Takemori, A. E. J Med Chem 1990, 33, 1714-1720.

22. Lomize, A. L.; Pogozheva, I. D.; Mosberg, H. I. Biopolymers 1996, 38, 221-234.

23. Backbro, K.; Lowgren, S.; Osterlund, K.; Atepo, J.; Unge, T.; Hulten, J.; Bonham, N. M.; Schaal, W.; Karlen, A.; Hallberg, A. J Med Chem 1997, 40, $898-$ 902.

24. Metzger, T. G.; Ferguson, D. M. FEBS Lett 1995, 375, $1-4$.

25. Conklin B. R.; Bourne, H. R. Cell 1993, 73, 631.

26. Bourne, H. R. Curr Opin Cell Biol 1997, 9, 134-142.

27. Lichtarge, O.; Bourne, H. R.; Cohen, F. E. Proc Natl Acad Sci USA 1996, 93, 7507-7511.

28. Baldwin, J. M. EMBO J 1993, 12, 1693-1703.

29. Chothia, C.; Lesk, A. M. EMBO J 1986, 5, 823-826.

30. Donnelly, D.; Overington, J. P.; Ruffle, S. V.; Nugent, J. H. A.; Blundell, T. L. Protein Sci 1993, 2, 55-70.

31. Taylor, W. R.; Jones, D. T.; Green, N. M. Proteins Struct Funct Genet 1994, 18, 281-294.
32. Donnelly, D.; Findlay, J. B. C.; Blundell, T. L. Receptors Channels 1994, 2, 61-78.

33. Lin, S. W.; Imamoto, Y.; Fukada, Y.; Shichida, Y.; Yoshizawa, T.; Mathies, R. A. Biochemistry 1994, 33, 2151-2160.

34. Kim, J. J.; Wess, J.; van Rhee, A. M.; Schoneberg, T.; Jacobson, K. A. J Biol Chem 1995, 270, 13987-13997.

35. Herzyk, P.; Hubbard, R. E. Biophys J 1995, 69, $2419-$ 2442.

36. Donnelly, D.; Findlay, J. B. C. Curr Opin Struct Biol 1994, 4, 582-589.

37. Ballesteros, J. A.; Weinstein, H. Meth Neurosci 1995, 25, 366-427.

38. McDonald, I. K.; Thornton, J. M. J Mol Biol 1994, 238, 777-793.

39. Lomize, A. L.; Pogozheva, I. D.; Mosberg, H. I. J Comput-Aid Mol Design 1999, 13, 325-353.

40. Altschuh, D.; Vernet, T.; Berti, P.; Moras, D.; Nagai, K. Protein Eng 1988, 2, 193-199.

41. Chen, C.; Xue, J.-C.; Zhu, J.; Chen, Y.-W.; Kunapuli, S. P.; de Riel, J. K.; Yu, L.; Liu-Chen, L.-Y. J Biol Chem 1995, 270, 17866-17870.

42. Fukuda, K.; Terasako, K.; Kato, S.; Mori, K. FEBS Lett 1995, 373, 177-181.

43. Hjorth, S. A.; Thirstrup, K.; Grandy, D. K.; Schwartz, T. W. Mol Pharmacol 1995, 47, 1089-1094.

44. Meng, F.; Hoversten, M. T.; Thompson, R. C.; Taylor, L.; Watson, S. J.; Akil, H. J Biol Chem 1995, 270, 12730-12736.

45. Pepin, M.-C.; Yue, S. Y.; Roberts, E.; Wahlestedt, C.; Walker, P. J Biol Chem 1997, 272, 9260-9267.

46. Heyl, D. L. Ph.D. thesis, University of Michigan, Ann Arbor, MI, 1991.

47. Heyl, D. L.; Mosberg, H. I. Int J Pept Protein Res 1992, $39,450-457$. 